\title{
Analysis and Solution of Dental Unit Failure
}

\author{
By J. J. Jin' ${ }^{1}$, H. Liu', K. Li ${ }^{2}$ Y. H. Chu' \\ ${ }^{1}$ Department of Clinical Medical Engineering, the Second Afpliated Hospital of Zhejiang University School of Medicine, Hangzhou \\ 310009, China \\ 2 Equipment Department, Ningbo Chinese Medicine Hospital, Ningbo 315010, China
}

\section{ABSTRACT}

Objective: To discuss and analyze the common causes of dental unit failures and summarize maintenance experiences.

Methods: The failures were studied through retrospective analysis in our dental clinic from January 2019 to December 2019. Causes for four common failures were analyzed deeply, and the corresponding improvement solution was implemented.

Results: These solutions reduced the failure rate for dental units and improved understanding of the importance of using and maintaining the equipment correctly.

Conclusion: Analysing and improving proper maintenance can save costs for the hospital and effectively enhance the management level of medical equipment maintenance.

Keywords - dental unit, failure, solution, maintenance.

Copyright (C) 2021. This is an open-access article distributed under the terms of the Creative Commons Attribution License (CC BY): Creative Commons - Attribution 4.0 International - CC BY 4.0. The use, distribution or reproduction in other forums is permitted, provided the original author(s) and the copyright owner(s) are credited and that the original publication in this journal is cited, in accordance with accepted academic practice. No use, distribution or reproduction is permitted which does not comply with these terms.

\section{INTRODUCTION}

With the improvement of people's living standards and the enhancement of oral health awareness, oral health has been paid more and more attention. The dental clinic of most domestic hospitals is often overcrowded, and the number of patients treated every day is much higher than in some foreign hospitals. The dental unit is a piece of essential medical equipment in the clinic. Since the establishment of BinJiang Hospital, 30 A-DEC dental units, including 4 A-DEC 500 units and 26 A-DEC 300 units, have been introduced and installed. With preventive maintenance and emergency repair by hospital engineers', they run stably. As we all know, dental units are generally composed of a dental chair, delivery system, cuspidor, and support center, dental light, etc. The schematic diagram is shown in Figure 1. 


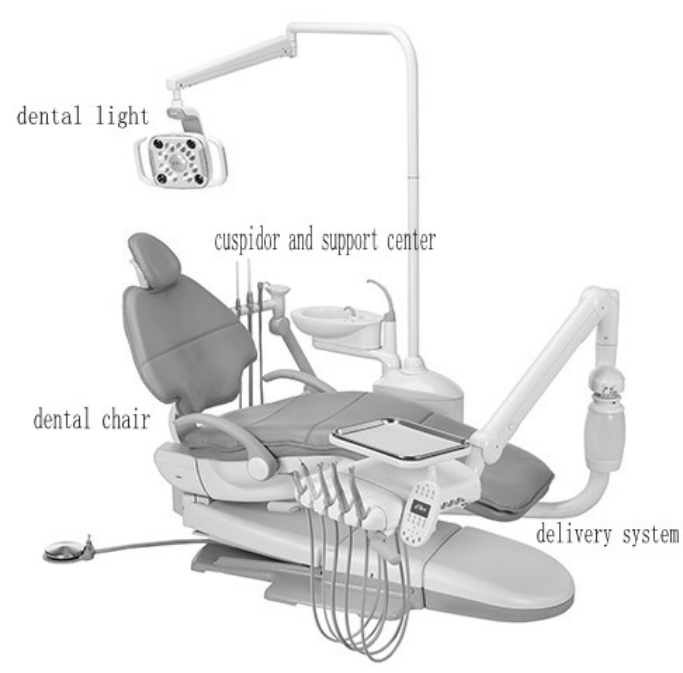

FIGURE 1. The schematic diagram of dental units.

The structure of dental unit is complex and includes a waterway, electrical circuits, and gas circuits. During the installation of the dental units, dealers generally recommend that the hospital use an independent water storage tank with pure water or a treated centralized water supply as oral treatment water. The hospital should use oil-free and dry air, in which the pressure is not less than $80 \mathrm{psi}$ to drive high-speed air-powered handpieces. Considering the actual diagnosis and treatment needs in China, most hospitals will choose a centralized water supply, and the water quality should meet the requirements of GB 57492006. After the dental units are installed, the hospital engineer will carefully check whether the functions of the equipment are normal and whether the accessories are consistent with the contract. However, many accessories may not be original but might be domestic accessories, so the service life cannot be accurately judged. During the use of the equipment, the manufacturer recommends preventive maintenance and regular replacement of some wearing parts. The hospital will also handle it according to the actual situation. To ensure the water quality of dental units, many domestic hospitals will regularly use sodium hypochlorite or other disinfectants to sanitize waterways. However, this solution will cause certain damage to the internal valve and pipeline of dental units and increase the failure rate, bringing some challenges to hospital engineers. ${ }^{1}$

As a maintenance engineer, the author has been responsible for oral-related equipment maintenance work for many years and has accumulated rich experience in maintenance. In the following, the author summarized and analyzed the care of our hospital dental units by using the A-dec brand as an example in recent years. From the engineers' point of view, the corresponding improvement measures were put forward to prevent and solve the common malfunctions for peer reference.

\section{Fault statistics}

According to the statistics, from January 2019 to December 2019, our hospital's dental unit received maintenance 780 times. Specific failure conditions are shown in Table 1 below. As can be seen from the table, the failure rate of dental units is relatively high in the waterways, electrical circuits, air circuits, and human factors. Particular failures include water pipe rupture, water valve failure, saliva ejector failure, and dental syringe accessories absence. ${ }^{2}$

\section{METHODS}

\section{Cause Analysis and Solution of Four Common Failures \\ Replace worn parts and plug potential water leaks}

The waterway is an essential part of the dental unit and provides the water supply during oral diagnosis and treatment. A water leakage problem is one of the most common malfunctions of the dental unit.

At the initial installation stage, the manufacturer equipped each unit with a water heater to heat the internal waterways. The structure of the heater was simple, the appearance of the heater was made of stainless steel, it was supplied by $24 \mathrm{~V}$ power, and the material of the inlet and outlet water pipes was brittle. Therefore, it was common to see cracks that can lead to water leakage after 2-3 years of use. This phenomenon had a high failure rate. Engineers assessed the situation and determined that the water leakage problem was caused by unapproved material supplied by the manufacturer. So the engineer comprehensively checked all the pipes inside all the dental chairs, recorded the pipe diameter and length details, purchased approved water pipes, and replaced the water pipes at potential leakage risk one by one to prevent the occurrence. After monitoring over time, all dental units did not have a recurrence of the problem. 
TABLE 1. Failure Statistical Table of Dental Units in 2019

\begin{tabular}{|c|c|c|c|c|c|}
\hline $\begin{array}{c}\text { Fault } \\
\text { Classification }\end{array}$ & Fault Point & Fault Phenomenon & Fault Cause & Number of Cases & Proportion \% \\
\hline \multirow{7}{*}{ Waterway } & \multirow{2}{*}{ Delivery system } & \multirow{2}{*}{$\begin{array}{c}\text { Handpiece drips water or no } \\
\text { water }\end{array}$} & Handpiece failure & 18 & 2.31 \\
\hline & & & Water valve failure & 38 & 4.87 \\
\hline & \multirow{5}{*}{$\begin{array}{l}\text { Cuspidor and } \\
\text { support center }\end{array}$} & Heater leakage water & Water pipe rupture & 19 & 2.43 \\
\hline & & \multirow{3}{*}{$\begin{array}{l}\text { Spittoon or gargle cup } \\
\text { leakage water or no water }\end{array}$} & Solenoid valve failure & 19 & 2.43 \\
\hline & & & Circuit board failure & 2 & 0.26 \\
\hline & & & Communication failure & 21 & 2.69 \\
\hline & & Cuspidor water contains air & Diaphragm rupture & 22 & 2.82 \\
\hline \multirow{13}{*}{ Circuit } & \multirow{3}{*}{ Dental chair } & \multirow{2}{*}{ Chair base can't move } & Circuit board failure & 2 & 0.25 \\
\hline & & & Communication failure & 13 & 1.67 \\
\hline & & Chair back can't move & Sensor failure & 1 & 0.13 \\
\hline & \multirow{5}{*}{ Delivery system } & Panel error & Panel failure & 22 & 2.82 \\
\hline & & \multirow{4}{*}{ Handpieces failure } & Pipeline rupture & 32 & 4.10 \\
\hline & & & Shelf valve loose & 46 & 5.90 \\
\hline & & & Handpiece failure & 15 & 1.92 \\
\hline & & & Circuit board failure & 5 & 0.64 \\
\hline & \multirow{3}{*}{$\begin{array}{l}\text { Cuspidor and } \\
\text { support center }\end{array}$} & \multirow{3}{*}{ No water } & Solenoid valve failure & 6 & 0.77 \\
\hline & & & Circuit board failure & 4 & 0.51 \\
\hline & & & Communication failure & 15 & 1.92 \\
\hline & \multirow{2}{*}{ Dental light } & \multirow{2}{*}{ Cannot work } & Bulb failure & 12 & 1.54 \\
\hline & & & Switch failure & 3 & 0.38 \\
\hline \multirow{7}{*}{ Gas Circuit } & \multirow{4}{*}{ Delivery system } & \multirow{4}{*}{ Handpiece failure } & $\begin{array}{l}\text { Handpiece lack of } \\
\text { driving gas }\end{array}$ & 5 & 0.64 \\
\hline & & & Improper regulation & 21 & 2.69 \\
\hline & & & Handpiece failure & 12 & 1.54 \\
\hline & & & Water pipe rupture & 31 & 3.97 \\
\hline & \multirow{3}{*}{$\begin{array}{l}\text { Cuspidor and } \\
\text { support center }\end{array}$} & Small negative pressure & Saliva ejector failure & 68 & 8.72 \\
\hline & & \multirow[b]{2}{*}{ No negative pressure } & Relay failure & 5 & 0.64 \\
\hline & & & $\begin{array}{l}\text { Positioning valve } \\
\text { malfunction }\end{array}$ & 11 & 1.41 \\
\hline \multirow{6}{*}{ Human Causes } & \multirow{6}{*}{ Delivery system } & Plate tilt & Overuse & 18 & 2.31 \\
\hline & & Handpiece failure & Incorrect setup & 5 & 0.64 \\
\hline & & Handpiece leakage water & Incorrect installation & 7 & 0.90 \\
\hline & & \multirow{2}{*}{$\begin{array}{l}\text { Handpiece no } \\
\text { Water }\end{array}$} & Panel incorrect setup & 5 & 0.64 \\
\hline & & & Water master switch off & 12 & 1.54 \\
\hline & & Dental syringe leakage water & Accessories absence & 74 & 9.49 \\
\hline
\end{tabular}


Jin, Liu, Li, Chu : Analysis and Solution of Dental Unit Failure

\begin{tabular}{|c|c|c|c|c|c|}
\hline $\begin{array}{c}\text { Fault } \\
\text { Classification }\end{array}$ & Fault Point & Fault Phenomenon & Fault Cause & Number of Cases & Proportion \% \\
\hline \multirow{5}{*}{ Human Causes } & Dental chair & Armrest failure & External force & 3 & 0.38 \\
\hline & $\begin{array}{l}\text { Cuspidor and } \\
\text { support center }\end{array}$ & Unreasonable Flush time & Incorrect setup & 81 & 10.38 \\
\hline & Footswitch & $\begin{array}{c}\text { Handpieces work } \\
\text { automatically when lift }\end{array}$ & Footswitch failure & 12 & 1.54 \\
\hline & \multirow{2}{*}{$\begin{array}{l}\text { Doctor's chair or } \\
\text { assistant chair }\end{array}$} & The assistant chair sprang up & Hydraulic failure & 59 & 7.56 \\
\hline & & Back failure & Lack of parts & 36 & 4.61 \\
\hline
\end{tabular}

Improve the existing structure to ensure adequate disinfection and instrument integrity

The study showed that the water supply of the dental unit was seriously polluted due to multiple factors such as the suction effect of the treatment instruments and water stagnation, and regular disinfection of the water, which is vital in controlling nosocomial infections. ${ }^{3}$ Our hospital disinfects the water pipes of dental units every quarter. The Hospital Infection Management Department uses a $500 \mathrm{mg} / \mathrm{L}$ sodium hypochlorite solution to disinfect the lines. The medical staff in the department of stomatology discharge water on all the effluent parts of dental units one by one, and the continuous discharge time shall not be less than 10 minutes so that the disinfectant can flow out of each terminal effluent point, ensuring effective disinfection. However, the high concentration of this chlorine-containing disinfectant can corrode the internal structure of the dental unit, mainly the valve, rubber band, and diaphragm. Specifically, high-speed handpieces, lowspeed handpieces, motors, and tooth cleaning machines hung on the valve after use will automatically leak water in varying degrees from spittoons and cup water spills. ${ }^{4}$ Looking back to 2019, this kind of failure frequently occurred about 3-5 days after each pipe disinfection, and several dental units leaked varying degrees.

Given this phenomenon, engineers searched for relevant information, consulted manufacturers, analyzed, and discussed the main reason for such failure. Specifically, the disinfectant had a particularly corrosive effect on the copper and rubber parts inside the dental unit. Specific damaged parts included water valve, solenoid valve assembly, diaphragm, etc. Considering the balance between disinfection effectiveness and the damage rate of the dental unit component, we proposed a preventive strategy. After each disinfection, the nurse extended the discharge water time to 20 minutes on the day. Before starting the machine, the nurse discharged water for 10 minutes every morning for the next 5 days to remove the residual disinfectant in the pipeline and reduce the corrosion of the disinfectant on the dental unit parts. Because the discharge water at all the outlet points of the existing dental unit cannot be controlled with one key, and the discharge and disinfection time cannot be controlled, the medical staff need to discharge water manually, which undoubtedly increases the workload of medical staff.

For this reason, based on existing dental units, our engineers have added an automatic discharge water control device. ${ }^{5}$ This design has been authorized national utility model patent. The specific structure is shown in Figure 2 below.

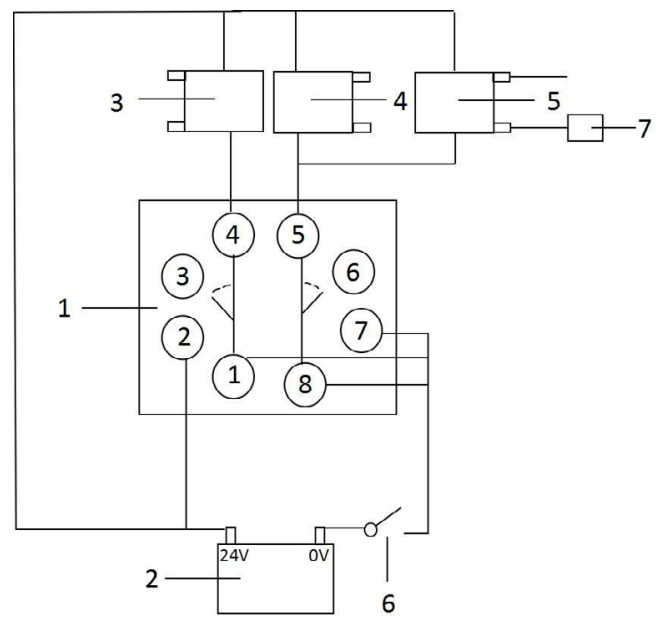

FIGURE 2. Structure drawing of automatic draw water control device. 
The specific working process is as follows: firstly, select the knob above of the time relay to $10 \mathrm{~min}$, and then press the switch, the time relay starts the timing, the exhaust solenoid valve opens, the backup air of dental unit will open four water valves in the water and air control module, four handpieces will drain away water at the same time, the solenoid valve of cup water and spittoon water will open, and cup water and spittoon water will also drain away water at the same time. After the timing is over, Pin 1 and Pin 4 of the time relay will disconnect, Pin 1 and Pin 3 will pull, Pin 5 and Pin 8 will disconnect, and Pin 6 and Pin 8 will pull. The exhaust solenoid valve, cup water solenoid valve, and spittoon water solenoid valve will stop working, The water valves in the water and air control module are closed, and the handpieces will not drain away water. Cup water solenoid valve and spittoon water solenoid valve are closed, cup water and spittoon water will stop drain away water. The clinical use of the device can not only realize the one-button control discharge of water and effective disinfection at all outlet points of the dental unit, but control the time of water discharge and disinfection accurately. However, this will also reduce the workload of medical staff and improve the compliance of medical staff in daily waterway disinfection, which is of great significance to clinical diagnosis and treatment in the department of stomatology.

\section{Do a good job of regular maintenance to reduce the occurrence of suction malfunction Attract tube}

Oral suction has a high utilization rate in daily oral diagnosis and treatment, and the subsequent failure rate is relatively high. The suction tube absorbs a large amount of dental debris and blood in the patient's oral cavity every day, and the oral pollutants are discharged underground through a long and thin tube, which is prone to pipe obstruction or suction failure. The negative pressure pump in the center of the hospital generates suction, and the positioning valve on the dental unit controls the start and stop of the negative pressure. Then the doctor can attract the patient's mouth through the suction tube to remove the dirt in the mouth. The main fault phenomena in the use process are suction pipe obstruction resulting in reduced suction, pipe aging rupture resulting in insufficient suction, positioning valve failure resulting in no negative pressure. If the suction malfunctions, it will negatively impact the doctor. For this kind of problem, engineers analyzed: (1) the high frequency of use, and (2) the lack of effective maintenance of the dental unit. Notably, medical staff only knew the use but did not know the regular maintenance for the suction tube. ${ }^{6}$ For this reason, the engineer actively communicated with the users of the equipment and formulated a routine maintenance items list for the dental chair according to the infection control guidelines recommended by the Centers for Disease Control and Prevention of the United States and the Australian Dental Association, ${ }^{7}$ as well as the manufacturer's maintenance manual. The guidelines were implemented in April 2020, and relevant records were made. The specific contents are shown in Table 2.

TABLE 2. Routine Maintenance Items List of Dental Units in Dental Clinics

\begin{tabular}{|c|c|c|}
\hline Project & Content & $\begin{array}{l}\text { Maintenance } \\
\text { Frequency }\end{array}$ \\
\hline \multirow{3}{*}{ Suction tube } & $\begin{array}{l}\text { After use, draw clean water } \\
\text { and rinse for } 1 \mathrm{~min}\end{array}$ & Once per person \\
\hline & $\begin{array}{l}\text { After treatment, detergent } \\
\text { was attracted for } 3 \mathrm{~min}\end{array}$ & Once per day \\
\hline & $\begin{array}{c}\text { Clean suction tube solid } \\
\text { strainer }\end{array}$ & Two times per week \\
\hline \multirow{2}{*}{ Handpieces } & $\begin{array}{l}\text { Flush the pipeline for } 2-3 \\
\text { min }\end{array}$ & Daily before use \\
\hline & Flush waterway for $20-30 \mathrm{sec}$ & $\begin{array}{c}\text { Between each } \\
\text { patient }\end{array}$ \\
\hline $\begin{array}{l}\text { Spittoon and } \\
\text { mouthwash } \\
\text { cup stand }\end{array}$ & Rinse and wipe & $\begin{array}{l}\text { Between each } \\
\text { patient }\end{array}$ \\
\hline
\end{tabular}

\section{Strengthen medical education to prevent the loss of dental syringe accessories}

Each dental unit in our hospital is equipped with a three-use spray gun for the doctor and a three-use spray gun for the assistant. Engineers often receive repair calls during daily use, such as leaking or unusable dental syringes. After careful observation of the use and malfunction of the three-use gun in the oral clinic, it was found that most malfunctions were caused by the absence of accessories. Engineers analyzed such problems mainly 
due to improper operation of medical staff and insufficient understanding of the spray gun structural components. Prevention measures could be taken from two aspects: First, strengthen the education and training of medical staff. The engineer communicated with the director of the department using the equipment and organized training on daily use and other matters of attention with the dental unit. This ensures that the medical staff can understand the structure of the dental unit, be familiar with the structure of the three-use gun, master the daily disassembly and assembly, and put the three-use gun into the daily inventory list. The nurse at each position was responsible for checking the related accessories of each tooth chair and reported if anything was missing. ${ }^{8}$ Second, engineers should strengthen regular inspection and prepare relevant accessories as needed.

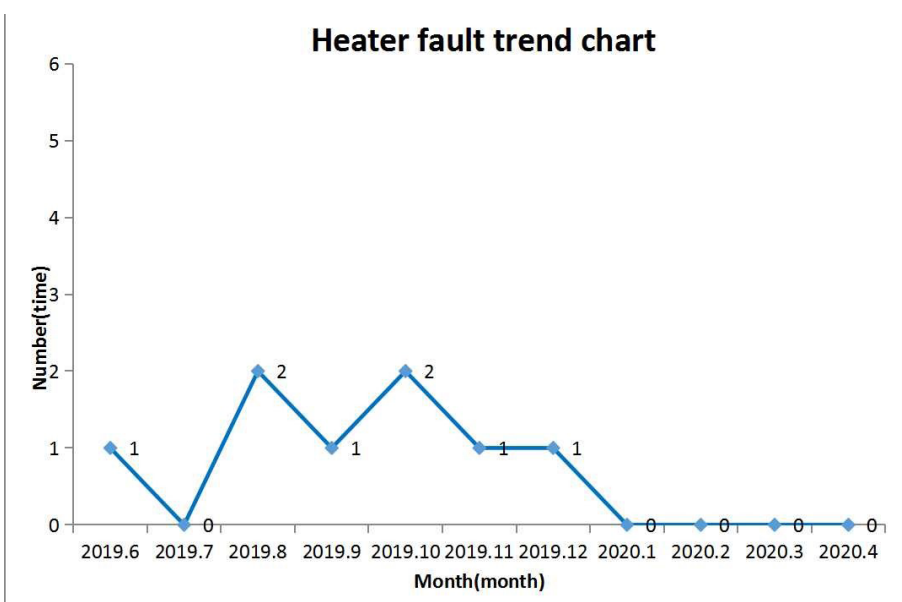

3(a). Heater fault trend chart

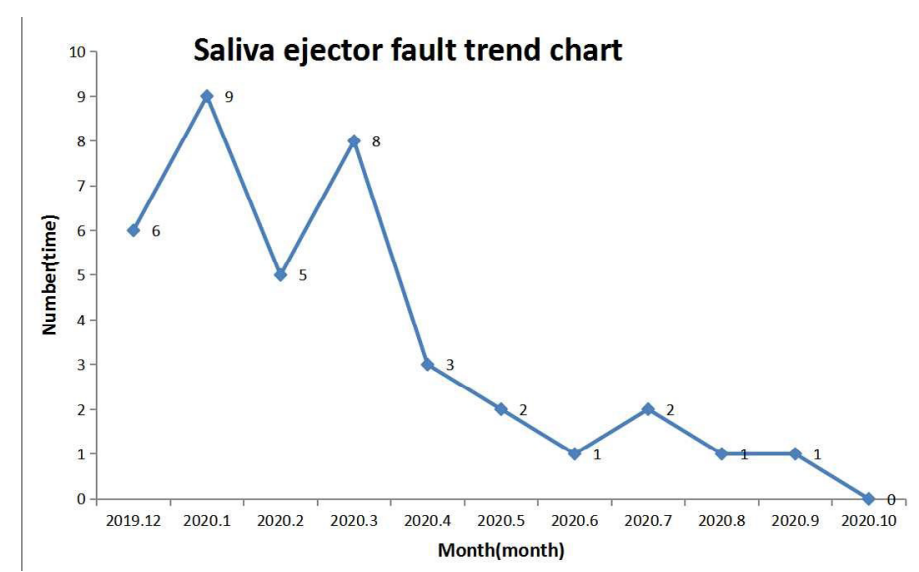

3(c). Saliva ejector fault trend chart

\section{RESULTS}

Since the beginning of 2020 , engineers have purchased and replaced all the internal pipes of our dental units to prevent water leakage from the heater. Figure 3 (a) shows the heater failure trend, and the number of failures is reduced to zero. After the dental unit pipes are disinfected, the failure rate of water valves are significantly reduced, and water valves replacement costs are saved through the installation of automatic discharge water control device and the implementation of relevant measures. Figure 3 (b) is the failure trend diagram of the water valve. Since the routine maintenance items list of the dental unit was implemented in April 2020, the saliva ejector's failure rate has decreased significantly. Figure 3 (c) shows the trend chart of the failure rate of the saliva ejector. In addition, since the management of the dental syringe was

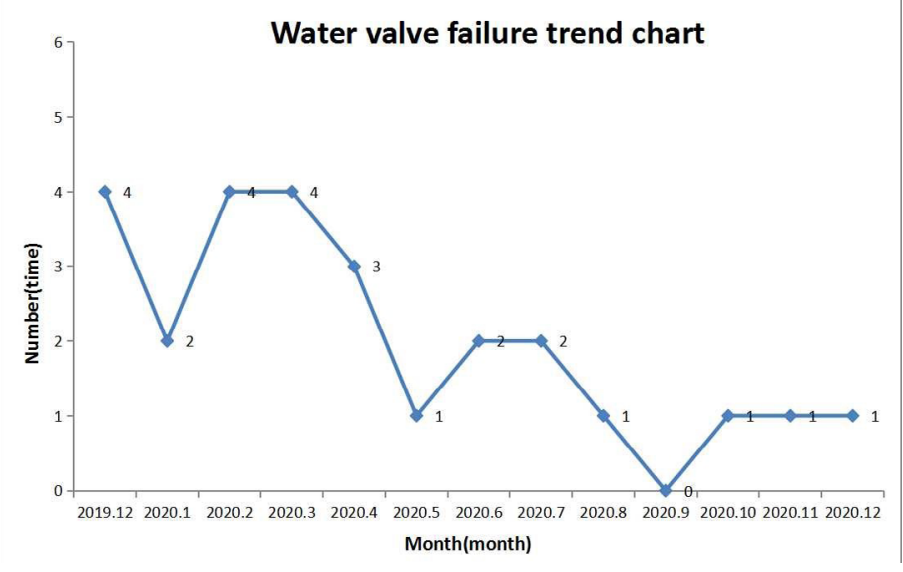

3(b). Water valve failure trend chart

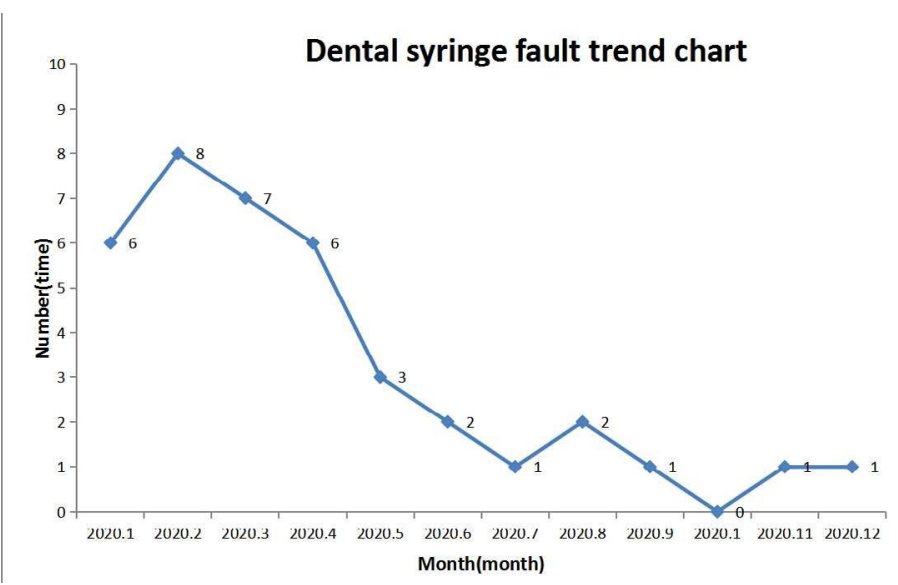

3(d). Dental syringe fault trend chart

FIGURE 3. Chart showing the different kinds of fault trends before and after improvement measures. 
strengthened in May 2020, the failure rate of the dental syringe decreased significantly. Figure 3 (d) shows the failure trend of the dental syringe.

Although the daily maintenance will increase a certain amount of work and maintenance time, it can effectively reduce the downtime of dental unit failure, reduce the number of repairs, reduce the repair expenditure, prolong the service life of the equipment, and improve the quality of clinical diagnosis and treatment. Comparison of items before and after maintenance are shown in Table 3. Among them, the average downtime was based on the time of failure to treat patients caused by each repair, and the average maintenance time was based on the time spent to complete the maintenance project. The average number of repairs was based on the number of repairs per dental unit in a year. The repair cost mainly includes replacing the water valve, saliva ejector, and position valve. The average repair expenditure was based on the repair expenditure per dental unit in one year.

TABLE 3. Comparison of Items Before and After Maintenance

\begin{tabular}{|c|c|c|}
\hline Items & $\begin{array}{c}\text { Before } \\
\text { Maintenance }\end{array}$ & $\begin{array}{c}\text { After } \\
\text { Maintenance }\end{array}$ \\
\hline Average downtime/ min & $20 \pm 5$ & $5 \pm 2$ \\
\hline Average maintenance time/ min & $3 \pm 1$ & $30 \pm 3$ \\
\hline Average number of repairs/time & $26 \pm 1$ & $5 \pm 1$ \\
\hline Average repair expenditure/ $¥$ & $353 \pm 3$ & $13 \pm 3$ \\
\hline
\end{tabular}

\section{DISCUSSION}

In this paper, by sorting out the common failure cases of the dental unit and selecting several typical problems with a high failure rate, the causes of the failures are deeply analyzed, and the corrective measures are put forward. ${ }^{9}$ The reasons for each failure type are analyzed from different perspectives in these cases, such as failing to replace wearing parts in time, inadequate equipment maintenance, incorrect operation, etc. There is also the question of balancing the requirements of hospital disinfection with the damage of dental unit components. Finally, engineers put forward the improvement schemes from their own point of view. The practice has proved that our dental units are running well, and the failure rate of several typical malfunctions is obviously reduced.

\section{CONCLUSIONS}

Maintenance engineers not only need to deal with daily failures but also need to deeply analyze the causes of failures and how to prevent similar failures. Medical engineers and technicians should use their professional knowledge to make appropriate innovations and feasible improvements to the existing equipment to solve the current problems. ${ }^{10}$ In the context of the current advanced management of medical equipment, engineers should improve their maintenance concepts, transform their experience into practical maintenance practices, and use information technology and quality management methods to improve medical equipment maintenance. ${ }^{11}$

\section{ACKNOWLEDGMENT}

We want to extend our sincere gratitude to Dr. Yadin David for his revising this paper. We are also deeply indebted to our other clinical engineering staff that supported our work.

\section{CONFLICT OF INTEREST}

The authors declare that they have no conflict of interest.

\section{REFERENCES}

1. Ma HX, Zhu J, Zhang M, et al. Research on maintenance optimization management method based on common fault analysis of oral comprehensive treatment table. Chinese J Med Equip 2019;16(3):132-135.

2. Li XY, Fan BL, Wu SB. Continuous improvement of the quality management of dental handpiece power deficiency in dental units. China Med Equip 2018;15(3):40-43.

3. Zhu CP, Yu XF. Research progress of dental comprehensive treatment waterlines system pollution and prevention. Nurs Rehabil J 2018;17(8):31-35.

4. Wang C, Liao X, Wang YT, et al. Biosafety evaluation of four disinfectants applied to microbial contamination control in dental unit waterlines. Oral Med 2019;39(7):596-600.

5. Lei JJ, Zhou W, Wang GH. Design of a simple waterlines disinfection device for dental unit. China Medical Equip 2018;15(6):168-169. 
6. Chen Y, Chen MR,Wang SD. Application of root cause analysis in reducing the failure rate of soft electronic endoscope. China Med Devices 2017;132(10):97-99,104.

7. Han M, Li XE, Lu Q. Research progress on contamination of dental unit waterlines. Chinese J Infect Control 2018;17(3):273-276.

8. Li Z, Zhong H, Cheng DS, et al. Analysis and solution to hemodialysis machine \& accessories faults. Chinese J Med lnstrument 2019;43(1):75-78.
9. Wang ZX, Wang EC, Chen YP. Retrospective analysis and countermeasures of OLYMPUS electronic endoscope failure. J Clin Nursing Practical 2019;4(28):190-192,196.

10.Jin JJ, Liu H, Chu YH. Maintenance of A-dec dental unit. Chinese J Med Device 2015;28(11):62-63.

11.Yin LN, Shao ZY, Zhang XP. Malfunction of dental high speed turbine handpiece and cause analysis: a retrospective study 7 years. Chinese J Modern Nurs 2020;26(9):1151-1155. 